\title{
Pattern of attendance and predictors of default among Nigerian outpatients with schizophrenia
}

\author{
AO Adelufosi', A Ogunwale ${ }^{2}$, AB Adeponle Ad, $^{3}$ Abayomi \\ 1Department of Psychiatry, Ladoke Akintola University Teaching Hospital, Ogbomoso, Oyo State, Nigeria \\ ${ }^{2}$ Neuropsychiatric Hospital, Aro, Abeokuta, Ogun State, Nigeria \\ ${ }^{3}$ Department of Psychiatry, University of Manitoba, Winnipeg, Manitoba, Canada.
}

\begin{abstract}
Objective: To assess the pattern of and factors associated with outpatient clinic attendance among patients diagnosed with schizophrenia at a Nigerian psychiatric hospital. Method: This was a cross-sectional descriptive study of 313 consecutive outpatients with diagnosis of schizophrenia confirmed with the Structured Clinical Interview for Diagnosis (SCID). Data was collected on sociodemographics, clinic attendance, perceived social support, perceived satisfaction with hospital care and illness severity (assessed using the Brief Psychiatric Rating Scale, BPRS). Logistic regression analysis was used to identify factors associated with outpatient clinic default. Results: Overall, $20.4 \%$ respondents were defaulters, with a median duration of clinic nonattendance of 8 weeks. Outpatient clinic defaulters had significantly higher BPRS scores and had missed more outpatient clinic appointments compared with non-defaulters. A significantly higher proportion of defaulters resided more than $20 \mathrm{~km}$ away from the hospital and reported "not satisfied" with their outpatient care. Being financially constrained was the commonest reason given by defaulters for missing their clinic appointments. The significant predictors of outpatient clinic default included residing more than $20 \mathrm{~km}$ from the hospital, missing previous appointments and dissatisfaction with outpatient care. Conclusion: Outpatient clinic non-attendance is common among patients with schizophrenia, and is significantly associated with demographic, clinical and service related factors. Interventions targeted at addressing the risk factors for defaulting peculiar to developing country settings similar to the location of this study, could significantly improve treatment outcome.
\end{abstract}

Keywords: Outpatients; Default; Schizophrenia; Non-attendance; Nigeria

Received: $28-09-2012$

Accepted: 08-10-2012

doi: http://dx.doi.org/10.4314/ajpsy.v16i4.38

\section{Introduction}

Outpatient clinic default in psychiatry is twice that in other medical specialties and is associated with poorer illness outcomes. ${ }^{1,2}$ Rates of treatment default as high as 30\% to 40\% have been reported in the United States and the United Kingdom and from developing countries. ${ }^{2-5}$ Aside poorer clinical and social outcomes, treatment default exerts a huge toll on families and society, one estimated at \$100 billion a year in the US. 6 While research has implicated a host of factors as predictive of psychiatric clinic default, findings have largely been inconsistent. . $^{4,7,7}$

\section{Correspondence}

Dr AO Adelufos

Department of Psychiatry, Ladoke Akintola University Teaching Hospital,

Ogbomoso, Oyo State, Nigeria

email: ozotee@gmail.com
In many low resource countries, the role of the family in support and care of persons with mental illness is of utmost importance. ${ }^{9}$ Recently, a study from Nigeria found family involvement in care to be protective against clinic default. ${ }^{10}$ However, in the aforementioned study, family involvement was assessed using criteria that may not reflect family support as subjectively perceived by the patients. Also there is a paucity of studies in the Nigerian setting regarding the influence of patient satisfaction with care on clinic attendance. In the present study, we assess the role of family involvement - as subjectively perceived by patients - on default and the association between patient satisfaction with care and clinic non-attendance. Since persistent outpatient clinic default may lead to eventual disengagement from outpatient services, we also examined patients' regularity of clinic attendance in order to identify an at-risk-population that may benefit from interventions aimed at reducing outpatient clinic default. 


\section{Methods}

Setting

The study was cross-sectional, involving patients attending the psychiatric outpatient clinic of the Neuropsychiatric hospital, Aro, Abeokuta, Nigeria. The hospital is a 526-bed facility that renders services to patients from Nigeria and other West African countries. Outpatient clinics are run four days a week. As such, patients who missed their prior scheduled follow-up appointments have the opportunity of attending on other clinic days within the week or at most the following week.

\section{Sample/data}

The sample size for this study was determined using the formula for calculating minimum sample size and 32.8\% prevalence of outpatient clinic missed appointments reported by a previous study in Nigeria. ${ }^{11,12}$ Eligible patients were those aged 18 - 64 years, who had attended the clinic for at least 6 months prior to the study (i.e. no new referrals), who had a diagnosis of schizophrenia confirmed using the Structured Clinical Interview for Diagnosis (SCID) and had at least one scheduled appointment during the study period. Severely disturbed patients and patients too ill to give coherent responses to questions were excluded from the study.

Using these inclusion criteria, 324 consecutive outpatient clinic attendees with a Diagnostic and Statistical Manual For Mental Disorders, Fourth Edition (DSM-IV) diagnosis of schizophrenia were approached and invited to participate in the study between June and November 2010. Out of these, 313 patients fully met the SCID diagnostic criteria for schizophrenia, while 11 patients did not and were excluded from the study.

Patients who failed to keep their clinic appointments on the scheduled date and who did not re-attend within two

(2) weeks following this date were operationally categorized as "defaulters". "Defaulters" who subsequently presented in the clinic during the study period were recruited onto the study and interviewed on the reasons for missing their previously scheduled appointments.

Although appointment intervals given to patients at the clinic vary based on patients' needs and on other factors such as distance of place of residence to the hospital etc., clinic visits are generally scheduled such that over a period of 6 months, a patient would have had at least four outpatient clinic appointments. Hence, in this study, respondents' regularity in attending the outpatient clinic was based on their attendance of the last four clinic appointments given and was categorized according to the following operational criteria:

i. Very regular: No appointments missed of the last four given

ii. Regular: Missed one appointment of the last four given

iii. Irregular: Missed 2-3 appointments of the last four given

iv. Very irregular: Missed all last 4 appointments.

Support received from family was measured on a Likertlike scale, as "good", "fair", or "poor", and satisfaction with the outpatient clinic services as "very satisfied", "moderately satisfied" or "not satisfied". Information was also collected on sociodemographic data, distance of patient's home from the hospital, living arrangement (i.e. whether living alone or with other people like family members, friends, and relatives etc.) and clinic appointment interval. The severity of psychopathology was rated using the Brief Psychiatric Rating Scale. ${ }^{13}$

\section{Data analysis}

Statistical analysis was done using the Statistical Package for Social Sciences (SPSS) version 15 (SPSS Inc, Chicago, IL, USA). Group comparisons were done using chi-square statistics for categorical data and student t-test for continuous variables. Logistic regression analysis was done to determine factors associated with outpatient clinic default. Predictor variables included in the logistic regression model were sociodemographic and clinical variables that had an association with defaulting at 0.05 level of significance. Odds ratios and 95\% confidence intervals were presented for the identified predictors.

\section{Ethics}

The study was approved by the Ethics and Research Committee of the Neuropsychiatric Hospital Aro, Abeokuta, Nigeria. After a detailed explanation of the study, respondents provided consents, mostly verbal but sometimes signed, before interviews were conducted. Consenting patients with case note diagnosis of schizophrenia were first interviewed using the SCID. Patients who met the diagnostic criteria for schizophrenia based on the SCID were then administered the socio-demographic questionnaires, followed by the the Brief Psychiatric Rating Scale (BPRS). The interviews were conducted after patients' routine clinic consultations.

\section{Results}

Of the 313 study participants, 163 (52.1\%) were male. The mean age was $39.5( \pm 10.71)$ years. Most respondents were single (44.4\%), had employment (60.7\%), and had up to secondary school education (36.1\%). A total of 183 (58.5\%) respondents had clinic appointment intervals between 5-12 weeks, 108 (34.5\%) had appointment intervals ranging from l-4weeks, and twenty-two (7\%) had appointment intervals greater than 12 weeks. The duration of respondents' illness ranged from 7 months to 43years with a median duration of 9.0 years. Three (1.0\%) of the respondents had been ill for less than lyear, 77 (24.6\%) for 1-4years, 92 (29.4\%) for 59years and 141 (45.0\%) for $\geq 10$ years. One hundred and sixty eight (53.7\%) respondents had no previous psychiatric hospitalizations, while 145 (46.3\%) had one or more previous admissions.

One hundred and fifty three (48.9\%) lived more than $50 \mathrm{~km}$ away from the hospital, and the majority (87.9\%) lived with family and relatives. Most (68.1\%) rated the support they enjoyed from family as "good", and majority (79.2\%) were "very satisfied" with the outpatient clinic care. Overall, 64 (20.4\%) respondents were categorised as defaulters while 249 (79.6\%) were non-defaulters. Duration of clinic nonattendance among the defaulters ranged from 3 - 364 weeks with a median of 8 weeks. Mean Brief Psychiatric Rating Scale (BPRS) score for defaulters and non-defaulters was 7.09 
$( \pm 8.49)$ and $3.48( \pm 5.03)$ respectively. Table I shows the distribution of outpatient clinic attendance and reasons given by defaulters for missing their appointments.

Respondents who resided less than $20 \mathrm{~km}$ from hospital were significantly less likely to be clinic defaulters compared to those who resided either $20-50 \mathrm{~km}$ away or more than $50 \mathrm{~km}$ away from hospital $(p=0.014)$. Compared to non-defaulters, defaulters had significantly missed more clinic appointments $(t=-5.091, p=$

\begin{tabular}{|c|c|c|}
\hline $\begin{array}{l}\text { Variable } \\
\qquad N=313\end{array}$ & Frequency & Percentage \\
\hline $\begin{array}{l}\text { CLINIC ATTENDANCE REGULARITY\# } \\
\text { Very Regular } \\
\text { Regular } \\
\text { Irregular } \\
\text { Very Irregular }\end{array}$ & $\begin{array}{l}185 \\
65 \\
48 \\
15\end{array}$ & $\begin{array}{l}59.1 \\
20.8 \\
15.3 \\
4.8\end{array}$ \\
\hline $\begin{array}{l}\text { OUTPATIENT CLINIC DEFAULT } \\
\text { Yes } \\
\text { No }\end{array}$ & $\begin{array}{l}64 \\
249\end{array}$ & $\begin{array}{l}20.4 \\
79.6\end{array}$ \\
\hline $\begin{array}{l}\text { DURATION OF CLINIC DEFAULT } \\
\text { AMONG DEFAULTERS (Weeks) } \\
\quad<4 \\
4-12 \\
>12 \\
\text { Median = } 8 \text { weeks } \\
\text { Range = 3-364 weeks }\end{array}$ & $\begin{array}{l}14 \\
30 \\
20\end{array}$ & $\begin{array}{l}21.9 \\
46.9 \\
31.2\end{array}$ \\
\hline $\begin{array}{l}\text { REASONS GIVEN FOR DEFAULTING } \\
\text { Financial Constraints } \\
\text { Felt well/better } \\
\text { Travelled } \\
\text { Very busy at work } \\
\text { Physically ill } \\
\text { Nobody to accompany patient } \\
\text { Clerical error }\end{array}$ & $\begin{array}{l}32 \\
20 \\
5 \\
4 \\
1 \\
1 \\
1\end{array}$ & $\begin{array}{l}50.0 \\
31.3 \\
7.8 \\
6.3 \\
1.6 \\
1.6 \\
1.6\end{array}$ \\
\hline \multicolumn{3}{|c|}{$\begin{array}{l}\text { \# - Very regular - Kept all last } 4 \text { appointments; Regular - Missed } 1 \text { of last } \\
\text { four appointments Irregular - Missed } 2 \text { or } 3 \text { of last four appointments; } \\
\text { Very irregular - Missed all last four appointments } \\
\ddagger n=64\end{array}$} \\
\hline
\end{tabular}

$<0.001$ ), had higher BPRS scores ( $\mathrm{t}=4.374, \mathrm{p}=<0.001)$ and were more dissatisfied with their outpatient care $\left(\chi^{2}=0.624, p=0.003\right)$. [Table II].

All variables significantly associated with outpatient clinic attendance in the univariate statistical analyses (BPRS score, distance from the hospital, satisfaction with treatment and number of missed clinic appointments) were entered into a logistic regression analysis (forward stepwise) to determine the independent correlates of outpatient clinic default. The result showed that only distance from the hospital, number of appointments missed and satisfaction with outpatient care remained significant in the analysis. The odds ratio and 95\% confidence interval of independently associated variables are presented in Table III.

\section{Discussion}

This study found an outpatient clinic default rate of $20.4 \%$ in a sample made up predominantly of patients with long-standing diagnosis of schizophrenia. We identified a sub-sample of "habitual" defaulters (20.1\%) who had missed two or more scheduled appointments before rescheduling. Regression analysis found factors associated with clinic default to be distance of home from hospital, number of appointments missed and satisfaction with outpatient care.

Our finding of a clinic default rate of $20.4 \%$ is lower than the $27.4 \%$ missed first attendance rate reported in a psychiatric outpatient clinic in Nigeria. ${ }^{12}$ However, new and long-term followup patients differ in their pattern of clinic attendance, aside the fact that our sample consisted entirely of patients with schizophrenia. ${ }^{2}$

An assessment of the outpatient clinic attendance pattern of all respondents showed that majority had missed at least one of the last four appointments given, comparable to the pattern of attendance reported in another study. ${ }^{14}$ Defaulters in this study had significantly missed more outpatient clinic appointments when compared with non-defaulters. Missing previous outpatient clinic appointments has been reported as a predictor of future clinic nonattendance. ${ }^{2}$

In the current study respondents who resided more than $20 \mathrm{~km}$ away from the hospital were more likely to be defaulters than those residing less than $20 \mathrm{~km}$ from the hospital. In addition, about $50 \%$ of the defaulters cited inadequate finances covering the cost of outpatient clinic visit as the reason for nonattendance. Indeed, majority of respondents in this study spent as much US \$13 - \$33 during each outpatient clinic visit, a cost

Table III: Predictors of Outpatient Clinic Non-attendance

\begin{tabular}{|c|c|c|c|c|c|c|}
\hline VARIABLE & $\beta$ & S.E & WALD & $d f$ & $p$ & OR $(95 \% \mathrm{Cl})$ \\
\hline $\begin{array}{l}\text { Distance From Hospital } \\
<20 \mathrm{~km} \\
20 \mathrm{~km}-50 \mathrm{~km} \\
>50 \mathrm{~km}\end{array}$ & $\begin{array}{l}- \\
1.998 \\
2.467\end{array}$ & $\begin{array}{l}- \\
0.854 \\
0.846\end{array}$ & $\begin{array}{l}- \\
5.469 \\
8.509\end{array}$ & $\begin{array}{l}- \\
1 \\
1\end{array}$ & $\begin{array}{l}- \\
0.019 \\
0.004\end{array}$ & $\begin{array}{l}\text { Reference Category } \\
7.372(1.382-39.326) \\
11.788(2.247-61.846)\end{array}$ \\
\hline $\begin{array}{l}\text { Satisfaction With Treatment } \\
\text { Not Satisfied } \\
\text { Moderately Satisfied } \\
\text { Very Satisfied }\end{array}$ & $\begin{array}{l}- \\
-3.261 \\
-2.785\end{array}$ & $\begin{array}{l}- \\
1.276 \\
1.204\end{array}$ & $\begin{array}{l}- \\
6.529 \\
5.349\end{array}$ & $\begin{array}{l}- \\
1 \\
1\end{array}$ & $\begin{array}{l}- \\
0.011 \\
0.021\end{array}$ & $\begin{array}{l}\text { Reference Category } \\
0.038(0.003-0.468) \\
0.062(0.006-0.654)\end{array}$ \\
\hline Number of Missed Appointments & 1.823 & 0.232 & 61.908 & 1 & $<0.001$ & $6.190(3.931-9.747)$ \\
\hline BPRS Score & 0.027 & 0.028 & 0.962 & 1 & 0.327 & $1.027(0.973-1.085)$ \\
\hline
\end{tabular}




\begin{tabular}{|c|c|c|c|c|c|}
\hline VARIABLE & $\begin{array}{l}\text { DEFAULTERS } \\
N=64 \\
\text { Mean } \pm S D ;\end{array}$ & $\begin{array}{l}\text { NON- DEFAULTERS } \\
N=249 \\
n(\%) \text { Mean } \pm S D ; n(\%)\end{array}$ & $\chi^{2}$ & $d f$ & $p$ \\
\hline $\begin{array}{l}\text { Gender } \\
\text { Male } \\
\text { Female }\end{array}$ & $\begin{array}{l}28(17.2) \\
36(24.0)\end{array}$ & $\begin{array}{l}135(82.8) \\
114(76.0)\end{array}$ & $1.835 \#$ & 1 & 0.135 \\
\hline $\begin{array}{l}\text { Religion } \\
\text { Christianity } \\
\text { Islam }\end{array}$ & $\begin{array}{l}39(17.5) \\
25(27.8)\end{array}$ & $\begin{array}{l}184(82.5) \\
65(72.2)\end{array}$ & $3.565 \#$ & 1 & 0.059 \\
\hline $\begin{array}{l}\text { Marital Status } \\
\text { Single } \\
\text { Married } \\
\text { Separated } \\
\text { Widowed } \\
\text { Divorced }\end{array}$ & $\begin{array}{l}18(13.0) \\
28(25.9) \\
9(26.5) \\
4(25.0) \\
5(29.4)\end{array}$ & $\begin{array}{l}120(87.0) \\
80(74.1) \\
25(73.5) \\
12(75.0) \\
12(70.6)\end{array}$ & 8.445 & 4 & 0.077 \\
\hline $\begin{array}{l}\text { Level of Education } \\
\text { None } \\
\text { Primary } \\
\text { Secondary } \\
\text { Tertiary }\end{array}$ & $\begin{array}{l}6(28.6) \\
23(27.4) \\
18(15.9) \\
17(17.9)\end{array}$ & $\begin{array}{l}15(71.4) \\
61(72.6) \\
95(84.1) \\
78(82.1)\end{array}$ & 5.133 & 3 & 0.162 \\
\hline $\begin{array}{l}\text { Employment Status } \\
\text { Employed } \\
\text { Unemployed }\end{array}$ & $\begin{array}{l}38(20.0) \\
26(21.1)\end{array}$ & $\begin{array}{l}152(80.0) \\
97(78.9)\end{array}$ & 0.010\# & 1 & 0.920 \\
\hline $\begin{array}{l}\text { Distance from Hospital } \\
<20 \mathrm{~km} \\
20-50 \mathrm{~km} \\
>50 \mathrm{~km}\end{array}$ & $\begin{array}{l}5(7.6) \\
23(24.5) \\
36(23.5)\end{array}$ & $\begin{array}{l}61(92.4) \\
71(75.5) \\
117(76.5)\end{array}$ & 8.550 & 2 & 0.014 \\
\hline $\begin{array}{l}\text { Perceived Social Support } \\
\text { Good } \\
\text { Fair } \\
\text { Poor }\end{array}$ & $\begin{array}{l}36(16.9) \\
22(28.6) \\
6(26.1)\end{array}$ & $\begin{array}{l}177(83.1) \\
55(71.4) \\
17(73.9)\end{array}$ & 5.220 & 2 & 0.074 \\
\hline $\begin{array}{l}\text { Living Arrangement } \\
\text { Alone } \\
\text { With Others }\end{array}$ & $\begin{array}{l}9(23.7) \\
55(20)\end{array}$ & $\begin{array}{l}29(76.3) \\
220(80.0)\end{array}$ & $0.098 \#$ & 1 & 0.754 \\
\hline $\begin{array}{l}\text { Satisfaction With Treatment } \\
\text { Not Satisfied } \\
\text { Moderately Satisfied } \\
\text { VerySatisfied }\end{array}$ & $\begin{array}{l}5(71.4) \\
10(17.2) \\
49(19.8)\end{array}$ & $\begin{array}{l}2(28.6) \\
48(82.8) \\
199(80.2)\end{array}$ & 0.624 & 2 & 0.003 \\
\hline $\begin{array}{l}\text { Appointment Length (weeks) } \\
1-4 \\
5-12 \\
>12\end{array}$ & $\begin{array}{l}30(27.8) \\
31(16.9) \\
3(13.6)\end{array}$ & $\begin{array}{l}78(72.2) \\
152(83.1) \\
19(86.4)\end{array}$ & 5.579 & 2 & 0.061 \\
\hline $\begin{array}{l}\text { Previous Hospital Admissions } \\
\text { Yes } \\
\text { No }\end{array}$ & $\begin{array}{l}28(19.3) \\
36(21.4)\end{array}$ & $\begin{array}{l}117(80.7) \\
136(78.6)\end{array}$ & $0.104 \#$ & 1 & 0.747 \\
\hline $\begin{array}{l}\text { CONTINUOUS VARIABLES } \\
\text { Age } \\
\text { Illness Duration (years) } \\
\text { Treatment Cost per Visit* } \\
\text { Number of Missed Appointments } \\
\text { BPRS Score }\end{array}$ & $\begin{array}{l}40.70 \pm 10.35 \\
9.97 \pm 7.18 \\
22.87 \pm 11.26 \\
2.30 \pm 1.18 \\
7.09 \pm 8.49\end{array}$ & $\begin{array}{l}39.18 \pm 10.81 \\
11.09 \pm 8.87 \\
24.35 \pm 16.69 \\
0.37 \pm 0.71 \\
3.48 \pm 5.03\end{array}$ & $\begin{array}{l}1.016 \dagger \\
-0.941 \dagger \\
-0.673 \\
-5.091 \dagger \\
4.374 \dagger\end{array}$ & $\begin{array}{l}311 \\
311 \\
311 \\
311 \\
311\end{array}$ & $\begin{array}{l}0.310 \\
0.347 \\
0.502 \\
<0.001 \\
<0.001\end{array}$ \\
\hline
\end{tabular}


which may be largely accounted for by the cost of transportation to the hospital, since almost half (48.9\%) of all respondents resided more than $50 \mathrm{~km}$ away from the hospital. The far distance of the hospital from their place of residences may add to whatever logistic and financial difficulties experienced by the patients in regularly keeping their outpatient appointments. Unfortunately, healthcare services, including mental health services, are largely provided on an out-of-pocket basis and there are no national social welfare schemes in Nigeria for patients with chronic mental illnesses, placing the financial burden of care on patients' relatives..$^{15}$ Hence, previous researchers in Nigeria have suggested a decentralization of psychiatric services and facilities through the establishment of functional community psychiatric practice as possible solution to reducing non-attendance rates in outpatient clinics. ${ }^{5,16}$

Outpatient clinic defaulters in this study also had significantly higher scores on the Brief Psychiatric Rating Scale, and thus more severe psychopathologies than non-defaulters. Outpatient clinic non-attendance is often associated with poor medication adherence, leading to poor mental state and failure of remission or recovery. In support of this finding was the observation by previous authors that outpatient clinic defaulters were more likely to have de-compensated in mental state at the time of presentation in the hospital and had a higher re-hospitalization rate than nondefaulters. ${ }^{16}$ For such defaulters, worsening or recurrence of psychopathological symptoms and deterioration in their quality of life might have precipitated a need to re-establish contact with the outpatient clinic.

The finding that a significant proportion of those who were dissatisfied with their outpatient care were defaulters is consistent with previous studies. ${ }^{17,18}$ Logistic regression analysis showed that those who were either moderately or very satisfied with their outpatient care were less likely to default. However, the specific aspects of outpatient care defaulters found unsatisfactory were not explored and this is one of the limitations of this study.

No significant relationship was found between clinic attendance and living arrangement. This was surprising in that it would have been expected that clinic attendance would be better among those living with family members by way of supervision and providing reminders. Thus, it is possible that patients in this study who lived alone had higher level of self-management which could have manifested as a tendency to keep clinic appointments. However, further studies will be needed to substantiate this.

Some important limitations of the current study must be addressed. The cross sectional nature did not permit the determination of the direction of causality. Second, the findings may not be generalizable to other parts of the country - or continent because it was conducted in one outpatient clinic in one part of Nigeria. Third, perceived social support and patients' satisfaction were not assessed with standardised instruments leaving them mainly at the level of face validity. Lastly, the results of this study were obtained from patients still in contact with the outpatient clinic despite previous non-attendance. Possibly, a different result might have been obtained if those that had dropped out of the treatment programme completely were included in the study.

Notwithstanding the aforementioned limitations, the strengths of this study lie in its moderately large sample size, an improvement upon previous similar studies conducted in Nigeria and its focus on patients with schizophrenia - since most studies have tended to focus on those with common mental disorders. In addition, this study provided a broader outline of possible risk factors for clinic non-attendance by including service related factors such as satisfaction with outpatient care.

\section{Conclusion}

The current study further highlights the need for a decentralization of mental health services through the implementation of community-based psychiatry in Nigeria. A nationwide implementation of primary healthcare based community psychiatry program, together with government subsidy of medication and treatment cost, may improve patients' access to services and possibly promote treatment adherence. It also emphasizes the need for improvement in both professional and administrative service delivery offered at outpatient clinics as a way of improving patients' satisfaction with care which will eventually translate into improved clinic attendance.

\section{References}

1. Mitchell AJ, Selmes T. Why don't patients attend their appointments? Maintaining engagement with psychiatric services. Advances in Psychiatric Treatment 2007b; 13: 423 - 434

2. Killaspy $H$, Banerjee $S$, King $M$, et al. Prospective controlled study of psychiatric outpatient, non-attendance. British Journal of Psychiatry 2000; 176: 160165.

3. Grunebaum M, Luber, $P$, Callahan, $M$, et al. Predictors of missed appointments for psychiatric consultations in a primary care clinic. Psychiatric Services 1996; 47: 848-852

4. Koch A, Gillis L S. Non-attendance of psychiatric outpatients. South African Medical Journal 1991; 80: 289 - 291.

5. Adeponle AB, Baduku AS, Adelekan ML, et al. Prospective Study of Psychiatric Follow-up Default and Medication Compliance after Discharge at a Psychiatric Hospital in Nigeria. Community Mental Health Journal 2009; 45: 19-25.

6. Breen R, Thornhill JT. Noncompliance with medication for psychiatric disorders. CNS Drugs 1998; 9:457-471.

7. Coodin S, Staley D, Cortens B, et al. Patient factors associated with missed appointments in persons with schizophrenia. Canadian Journal of Psychiatry 2004; 49: 145-148.

8. Sharp D, Hamilton W. Non-attendance at general practices and outpatient clinic. British Medical Journal 2001; 323: 1081-1082.

9. Gureje O, Alem A. Mental health policy development in Africa. Bulletin of the World Health Organisation 2000; 78(4): 475-482.

10. Adeponle AB, Thombs BD, Adelekan ML, et al: Family participation in treatment, post-discharge appointment and medication adherence at a Nigerian p.sychiatric hospital. The British Journal of Psychiatry 2009; 194: 86 - 87.

11. Lwanga S, Lemeshow S. Sample size determination in health Studies: a practical manual. World Health Organization, Geneva, 1991; 23-30.

12. Adeponle AB, Obembe AO, Suleiman GT, et al. Missed first appointments Prevalence and associated factors in first time attendees at an outpatient psychiatric clinic in Nigeria. Mental Health \& Religion \& Culture 2007; 1 - 2.

13. Overall JE, Gorham DR. The Brief Psychiatric Rating Scale. Psychological Reports 1962; 10: 799-812.

14. Lim LEC, Poo KP, Lein T, et al. Why patients fail to attend psychiatric outpatient follow up: a pilot study. Singapore Medical Journal 1995; 36: 403-405.

15. Sulaiman TG, Ohaeri JU, Lawal RA, et al. Financial cost of treating outpatients with schizophrenia in Nigeria. British Journal of Psychiatry 1997; 171:364-368.

16. Adelekan ML, Ogunlesi AO. Defaulting at the Nigerian National Neuropsychiatric Hospital. Psychiatric Bulletin 1990; 14: 403 - 405.

17. Young AS, Crusky O, Jordan D. Routine outcome monitoring in a public mental health system- the impact of patients who leave care. Psychiatric Services 2000; 51: 85-91.

18. Rossi A, Amaddeo F, Bisoffi G, et al. Dropping out of care: inappropriate terminations of contact with community based psychiatric services. British Journal of Psychiatry 2002; 181: 331-338. 